\title{
Effect the Mechanism of Emodin Combined with Cp-1 on Proliferation and Apoptosis of Bladder Cancer Cell Line BIU-87
}

\author{
BI-XIA YU AND BIN-BIN YANG ${ }^{1 *}$
}

The Biobank of Ningbo First Hospital, ${ }^{1}$ Department of Urology, Ningbo First Hospital, 59 Liuting Street, Ningbo, Zhejiang 315010, China

Yu et al.: Mechanism of Emodin Combined with Cp-1 on Cancer Cell Line BIU-87

\begin{abstract}
To investigate the effect of emodin combined with $\mathrm{Cp}-1$ on the proliferation and apoptosis of bladder cancer cell line BIU-87. BIU-87 cells were randomly divided into control group, Cp-1 group, emodin group, Cp-1 combined with emodin group. Flow cytometry was used to detect the apoptosis of BIU-87 cells. 3-(4,5-dimethylthiazol-2-yl)-2,5-diphenyl tetrazolium bromide assay was used to detect the proliferation of BIU-87 cells. Western blot and reverse transcription-polymerase chain reaction were used to detect the recepteur d'origine nantais, Caspase-3 and B-cell lymphoma 2 expressions. Compared with control group, the cell survival rate of $\mathrm{Cp}-1$ group, emodin group and $\mathrm{Cp}-1$ combined with emodin groupwas significantly decreased, especially in Cp-1 combined with emodin group, which was significantly lower than that of Cp-1 group and emodin group $(\mathbf{p}<\mathbf{0 . 0 5})$, while the cell apoptosis rate of $\mathbf{C p}-1$ group, emodin group and $\mathbf{C p}-1$ combined with emodin group was significantly increased, especially in $\mathrm{Cp}-1$ combined with emodin group, which was significantly higher than that of $\mathrm{Cp}-1$ group and emodin group $(\mathrm{p}<0.05)$ and the expression of recepteur d'origine nantais decreased significantly $(p<0.05)$. Inhibition of recepteur d'origine nantais expression suppressed B-cell lymphoma 2 and increased Caspase-3 significantly $(\mathrm{p}<0.05)$. Our results indicated that emodin combined with Cp-1 could enhance the apoptosis and inhibit proliferation of bladder cancer cells. The mechanism may be that emodin can inhibit the expression of recepteur d'origine nantais, down regulated the expression of B-cell lymphoma 2, which increased the expression of caspase-3 in bladder cancer cells and promoted the apoptosis of bladder cancer cells.
\end{abstract}

Key words: Bladder cancer, emodin, Cp-1, apoptosis, cell proliferation

Bladder cancer is a common tumor of genitourinary system. The incidence of bladder cancer is 7.49/104 in the tumor registration areas nationwide, accounting for $2.5 \%$ of the incidence of malignant tumors in China $^{[1]}$. There are many pathological types of bladder cancer, mainly including urothelial carcinoma, squamous cell carcinoma, adenocarcinoma and small cell carcinoma, among which urothelial carcinoma is the most common one ${ }^{[2]}$. The pathogenesis of bladder cancer is still unclear and the biological processes involved are very complex, including numerous gene mutations, chromatin recombination and changes in kinase signaling pathways ${ }^{[3]}$. Bladder cancer brings a huge economic burden to people and threatens human health. Therefore, it has become urgent to deepen the understanding of the pathogenesis of bladder cancer and to find an effective treatment.
Macrophage stimulating protein receptor, recepteur d'origine nantais ( $\mathrm{RON}$ ), belongs to the tyrosine kinase receptor in the MET proto-oncogene family. Studies have found that RON is highly expressed in bladder cancer and its expression is correlated with the prognosis of patients with bladder cancer ${ }^{[4]}$, but its role and related mechanism in bladder cancer remain to be clarified. Emodin, chemically known as 1,3,8-trihydroxy-6methylanthraquinone, molecular formula: $\mathrm{C} 15 \mathrm{H} 10 \mathrm{O} 5$, molecular weight: 270.23 , is one of the main active components of traditional Chinese medicine rhubarb and is also abundant in many traditional Chinese medicines such as Polygonum cuspidatum, Polygonum multiflorum, Radix Dioscorea and Lilium lilium. Studies have shown that emodin can inhibit the growth of lung adenocarcinoma cells ${ }^{[5]}$, human glial cells ${ }^{[6]}$, human chronic myelogenous leukemia cells ${ }^{[7]}$, human rectal

*Address for correspondence

E-mail: 3556184924@qq.com 
cancer cells ${ }^{[8]}$ and other tumor cells, but the mechanism of its anti-tumor action is still unclear. $\mathrm{Cp}-1$ is a small molecule inhibitor of tyrosine kinase RON activity. $\mathrm{Cp}-1$ is a small molecule inhibitor of receptor tyrosine kinase RON activity. It has been found that emodin can exert a certain inhibitory effect on tyrosine kinase, but its mechanism has not been reported yet. In this study, RON inhibitor Cp-1 and emodin were combined to act on bladder cancer cell line BIU-87 to observe the changes of cell proliferation and apoptosis and to explore the mechanism.

\section{MATERIALS AND METHODS}

\section{Cells and main experimental materials}

This work was supported by the Fund of clinical study on the prevention Methods of neonatal nasal injury during nasal continuous positive airway pressure (No. FY2019-105).

The bladder cancer cell line BIU-87 was provided by the Cell Bank of Shanghai Institute of Biochemistry, Chinese Academy of Sciences. Emodin (purity $>98 \%$, purchased from Sima, USA) is dissolved in physiological saline with Dimethyl sulfoxide (DMSO) concentration $<0.1 \%$ (volume fraction). PC-1 was purchased from American Sigma Company. 3-(4,5-dimethylthiazol-2yl)-2,5-diphenyl tetrazolium bromide (MTT) reagents were purchased from AMRESCO, USA. The apoptosis detection kit (FITC Annexin V Apoptosis Detection Kit 1) was purchased from BD Company, USA. $2.5 \%$ Ethylenediamine tetraacetic acid (EDTA)-pancreatin was purchased from Gibco, USA, hematoxylin and eosin stain were purchased from Beijing Zhongshan Jinqiao Company, Cell Counting Kit-8 (CCK-8) kit, 4',6-diamidino-2-phenylindole (DAPI) detection solution, Ribonucleic acid (RNA) extraction kit, protein extraction kit (Beijing Soleibao Bio Co., Ltd.); Bax, B-cell lymphoma 2 (Bcl-2), caspase-3, $\alpha$-tubulin (internal reference) primary antibodies (Proteintech Group); Bax, Bcl-2 and caspase-3 primers were designed and synthesized by Beijing Kinco Biological Co., Ltd.

\section{Cell culture}

BIU-87 cells were cultured in RPMI-1640 medium containing $10 \%$ fetal bovine serum, placed in a $5 \%$ $\mathrm{CO} 2,37^{\circ}$ constant temperature and humidity incubator, to keep the cells in a monolayer adherent growth. The cells were digested and passaged with trypsin containing $2.5 \%$ EDTA every $2 \mathrm{~d}$.
Cell grouping and drug administration

BIU-87 cells were divided into control group (group B), Cp-1 group (group C), emodin group (group D), and $\mathrm{Cp}-1$ combined with emodin group (group $\mathrm{CD}$ ). Groups C, D and CD were added with Cp-1, emodin and $\mathrm{Cp}-1+\mathrm{emodin}$, respectively and various drugs were added with concentration of half maximal inhibitory concentration (IC50). Group B was added with the same amount of DMSO solution without drugs.

\section{Cell proliferation assay}

The cells in the logarithmic growth phase were digested with trypsin, and $100 \mu \mathrm{L}$ (containing $5 \times 10^{3}$ cells) of the suspension was seeded in a 96-well plate. After the cells adhered, the corresponding drugs were added to each group. After $72 \mathrm{~h}$, add $20 \mu \mathrm{L}$ of MTT $(5 \mathrm{mg} / \mathrm{mL})$ to each well and incubate in a cell culture incubator. After $4 \mathrm{~h}$, centrifuge at $1200 \mathrm{r} / \mathrm{min}$ for $10 \mathrm{~min}$ and discard the supernatant. Add $200 \mu \mathrm{L}$ of DMSO to each well and mix on a shaker for $30 \mathrm{~min}$ until the crystals are completely dissolved. Use a microplate reader to measure the Optical Density (OD) value at a wavelength of 530 $\mathrm{nm}$. Cell survival rate $=$ (experimental group OD valueblank group OD value)/(control group OD value-blank group OD value $) \times 100 \%$. The experiment was repeated three times.

\section{Apoptosis assay}

$1 \times 10^{5}$ logarithmic growth cells were seeded into 6-well plates and cultured for $24 \mathrm{~h}$. The original culture medium was discarded after cells attached the wall. Add the appropriate medicine. $72 \mathrm{~h}$ later, all the cells were digested by trypsin and collected in a $5 \mathrm{ml}$ test tube. The cells were centrifuged at $1500 \mathrm{r} / \mathrm{min}$ for 5 min. Remove the supernatant, and wash once with physiological saline. Add $1 \times$ Binding Buffer to adjust the cell concentration to $1 \times 10^{6} / \mathrm{mL}$ and take $100 \mu \mathrm{L}(1 \times 105$ cells) into a new $5 \mathrm{ml}$ test tube. Add $5 \mu$ Fluorescein isothiocyanate (FITC) and $5 \mu$ Propidium Iodide (PI) to each tube and hide tubes from light for $15 \mathrm{~min}$ at room temperature. Add $400 \mu \mathrm{L} 1 \times$ Binding Buffer before loading, and the cell apoptosis was observed by flow cytometry within $1 \mathrm{~h}$. The experiment was repeated for 3 times.

\section{Reverse transcription-polymerase chain reaction (RT-PCR) assay}

Take $1 \times 10^{5}$ cells in the logarithmic growth phase and inoculate them in a 6-well plate and culture for $24 \mathrm{~h}$. 
After cells sticking to the wall, the original culture medium was discarded and corresponding drugs were added to each group. The cells were collected after 48 and $72 \mathrm{~h}$ of treatment and the total RNA of each group was extracted according to the Trizol kit instruction. The total RNA was reverse transcribed into the first strand of Complementary DNA (cDNA) by Promega reverse transcription kit.

The Messenger RNA (mRNA) expression levels of RON, Bcl-2 and Caspase-3 were detected by RT-PCR with Glyceraldehyde 3-phosphate dehydrogenase (GAPDH) as internal reference. The reaction procedure was set as follows: predenaturation at $95^{\circ}$ for $30 \mathrm{~s}$, denaturation at $95^{\circ}$ for 5 $\mathrm{s}$, annealing and extension at $60^{\circ}$ for $34 \mathrm{~s}, 40$ cycles and 3 replicate holes for each sample. The experiment was repeated three times. The primer sequences of this study are: RON: upstream primer sequences: 5 ' - T G GCA GC T GA CATG T T T T C T GA C - 3' ; downstream primer sequences: 5 ' - T C A C C C A A C C A C C C T G G T C T T- 3'; Bcl-2: upstream primer sequences: 5' - T C G C C C T G T G G A T G A C T G A - 3'; downstream primer sequence 5' - CA GA GA C A G C C A GGA GAAAT CA - 3'; Caspase-3: upstream primer sequence 5' - C T G G A C T G T G G C A T T G A G A C - 3'; downstream primer sequence 5'-ACAAAGCGACTGGATGAACC-3'.

\section{Western blot assay}

Take $1 \times 105$ cells in the logarithmic growth phase and inoculate them in a 6-well plate and culture for $24 \mathrm{~h}$. After cells sticking to the wall, the original culture medium was discarded and the corresponding drugs were added to each group. The cells were collected after 48 and $72 \mathrm{~h}$ of treatment and the protein was extracted according to the total protein extraction kit. The total protein concentration of the cells was determined by Bicinchoninic acid (BCA) assay method.

\section{Main observation indicators}

Inhibition rate of cell proliferation; Apoptosis; Expression of RON, Bcl-2 and caspase-3 mRNA; Expression of RON, Bcl-2 and caspase-3 protein.

\section{Statistics and analysis}

The results were statistically processed with Statistical Package for the Social Sciences (SPSS) 20.0 statistical software. Measurement data were expressed as $\mathrm{x} \pm \mathrm{s}$.
One-way Analysis of variance (ANOVA) was used in compare among multiple groups. $\mathrm{p}<0.05$ was considered statistically significant.

\section{RESULTS AND DISCUSSION}

Compared with group $\mathrm{B}$, the cell survival rate in groups $\mathrm{C}, \mathrm{D}$ and $\mathrm{CD}$ was significantly decreased and the decrease in group CD more obviously, which was significantly different from that in groups $\mathrm{C}$ and $\mathrm{D}$, with statistical significance $(p<0.05)$. Although the cell survival rate of group $\mathrm{C}$ was lower than that of group $\mathrm{D}$, there was no significant difference between the two groups ( $\mathrm{p}>0.05)$, as shown in fig. 1 and Table 1 .

\section{TABLE 1: COMPARISON OF CELL PROLIFERATION} INHIBITION RATES IN EACH GROUP

\begin{tabular}{ccccc}
\hline & Group B & Group C & Group D & Group CD \\
\hline $24 \mathrm{~h}$ & $1.42 \pm 0.64$ & $10.67 \pm 0.23$ & $11.89 \pm 0.37$ & $43.56 \pm 1.09$ \\
$48 \mathrm{~h}$ & $1.63 \pm 0.53$ & $21.55 \pm 0.3$ & $22.35 \pm 0.72$ & $54.83 \pm 2.45$ \\
$72 \mathrm{~h}$ & $1.18 \pm 0.72$ & $35.27 \pm 0.82$ & $36.67 \pm 1.46$ & $75.13 \pm 1.63$ \\
\hline
\end{tabular}

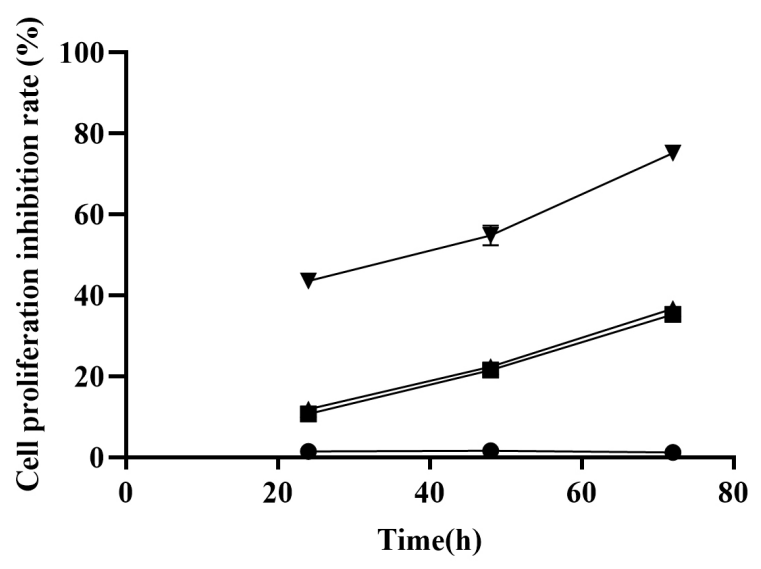

Fig. 1: Inhibition of cell proliferation in each group $(-\bullet)$ B; $(\neg-) \mathrm{C} ;(\neg-) \mathrm{D} ;(\rightarrow-) \mathrm{CD}$.

Compared with group B, the apoptosis rate of groups $\mathrm{C}, \mathrm{D}$ and $\mathrm{CD}$ was significantly increased, among which the proportion of group CD was increased more obviously and with significant differences compared with groups $\mathrm{C}$ and $\mathrm{D}(\mathrm{p}<0.05)$. Although the apoptosis rate of group $\mathrm{C}$ was higher than that of group $\mathrm{D}$, there was no significant difference between the two groups ( $>0.05$ ), as shown in Table 2 and fig. 2.

TABLE 2: COMPARISON OF THE PROPORTION OF APOPTOSIS IN EACH GROUP

\begin{tabular}{ccccc}
\hline & Group B & Group C & Group D & Group CD \\
\hline $24 \mathrm{~h}$ & $1.12 \pm 0.38$ & $15.81 \pm 0.54$ & $14.94 \pm 0.43$ & $45.62 \pm 1.11$ \\
$48 \mathrm{~h}$ & $1.43 \pm 0.33$ & $32.62 \pm 0.71$ & $32.95 \pm 0.61$ & $57.37 \pm 2.43$ \\
$72 \mathrm{~h}$ & $1.58 \pm 0.39$ & $43.63 \pm 0.81$ & $45.54 \pm 0.93$ & $77.64 \pm 2.55$ \\
\hline
\end{tabular}




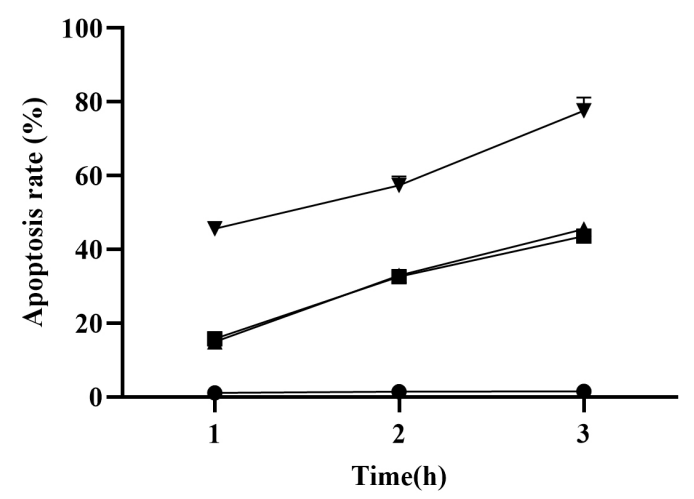

Fig. 2: Cell apoptosis in each group $(-\rightarrow) \mathrm{B}$; $(--) \mathrm{C}$; $\left(-\leftarrow_{-}\right) \mathrm{D}$; $(\rightarrow-)$ CD.

In group $\mathrm{B}$, the relative of RON mRNA and protein expression in each group at $72 \mathrm{~h}$ after drug adding was shown in fig. 3. The experimental results showed that compared with group $\mathrm{B}$, the expression of each intervention group was significantly decreased and the difference was statistically significant $(\mathrm{p}<0.05)$, among which the expression of group $\mathrm{CD}$ had the greatest change and the difference was statistically significant compared with group $\mathrm{C}$ and $\mathrm{D}(\mathrm{p}<0.05)$, but there was no significant difference between group $\mathrm{C}$ and $\mathrm{D}$ $(p>0.05)$. The results showed that emodin inhibited tyrosine kinase and had a synergistic effect with $\mathrm{Cp}-1$.
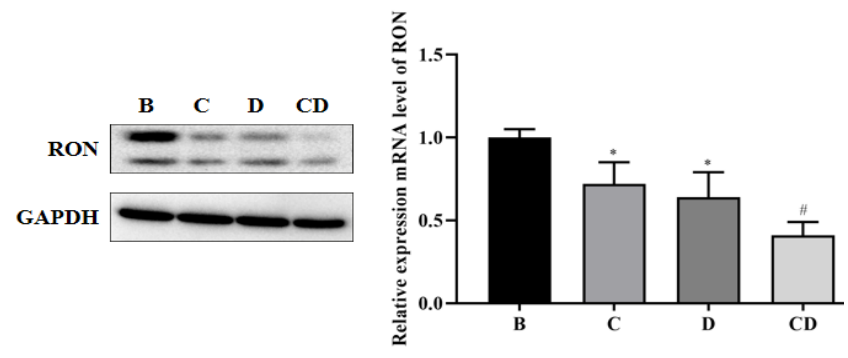

Fig. 3: RON expression in each group ( $\mid$ ) B; ( 口 ) C; ( ロ ) D; ( ロ) CD.

Note: *Compared with $B$ group, $\mathbf{p}<0.05$; \#Compared with $\mathbf{C}$ and $D$ groups, $\mathrm{p}<0.05$.

In group $\mathrm{B}$, the relative mRNA and protein expression levels of Bcl-2 and Caspase-3 in each group after inhibition of RON were shown in fig. 4. The results showed that there were significant differences between the treatment groups and the control group $(p<0.05)$, in which the expression level of caspase-3 was significantly increased and the expression level of Bcl-2 was significantly decreased. The expression level of CD group had the greatest change and the difference was statistically significant when compared with group $\mathrm{C}$ and group $\mathrm{D}(\mathrm{p}<0.05)$, but there was no significant difference between group $\mathrm{C}$ and group $\mathrm{D}$ $(p>0.05)$. These results showed that emodin and $\mathrm{Cp}-1$ promoted apoptosis of BIU-87 cells by up-regulating the expression of Caspase- 3 and down-regulating the expression of Bcl-2.
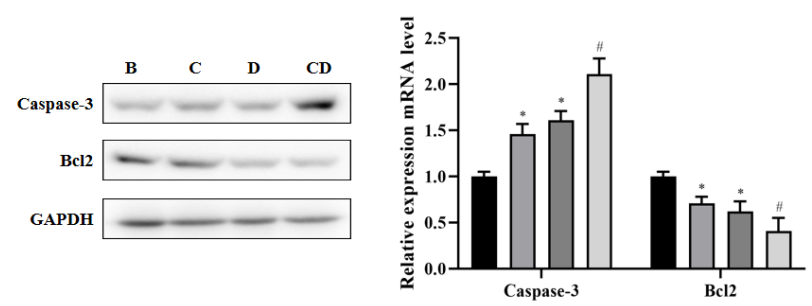

Fig. 4: The levels of Bcl-2 and Caspase-3 expression in each group ( $\mid$ - ) B; ( ص) C; ( ص) D; ( ص) CD.

Note: *Compared with $B$ group, $p<0.05$; ${ }^{\#}$ Compared with $C$ and D groups, $\mathbf{p}<0.05$.

Bladder cancer is a heterogeneous tumor with a high incidence in men and is the fourth leading cause of death from cancer in men. Studies have confirmed that heavy drinking and smoking are risk factors for bladder cancer ${ }^{[9]}$. The choice of treatment depends on the tumor pathological grade and stage, primary tumor resection or combined with bladder perfusion of chemotherapy drugs were mainly used for early non-muscular infiltrating bladder cancer, while radical cystectomy was mainly used for muscular infiltrating bladder cancer and the prognosis of patients was significantly improved with the combined application of neoadjuvant systemic chemotherapy and radiotherapy ${ }^{[10]}$. However, bladder cancer has a very high rate of recurrence and metastasis. Currently, there is no effective treatment for recurrent and metastatic bladder cancer, so it is particularly important to develop a new treatment method.

In recent years, epigenetic regulation has gradually become a focus of tumor research and the existence of abnormal epigenetic regulation in tumors has been gradually confirmed. Drugs targeting epigenetic regulation have been applied in clinical trials and are very promising ${ }^{[7,11]}$. RON receptor tyrosine protein kinase can act as a common signal transduction component in a variety of signal transduction pathways. It can regulate gene expression, participate in a series of important biological processes such as cell cycle, cell growth, apoptosis and inflammation is related to the occurrence and development of tumors. Cp-1, as the RON inhibitor, can bind to Cys-773 in the catalytic domain of growth factor receptor and $\mathrm{RON}$ receptor in a ratio of $1: 1$ to block the signaling pathway of RON receptor-tyrosine 
kinase. It has been reported in the literature that compared with normal cells, the growth and progress of RON positive tumor cells more significantly rely on RON signal transduction ${ }^{[12,13]}$. Blocking the RON signaling pathway can significantly impair tumor viability in vivo and in vitro and enhance its response to radiation and cytotoxic mediated killing. Emodin is a natural anthraquinone derivative first extracted from rhubarb and is a tyrosine kinase inhibitor ${ }^{[4]}$. Its role in inducing tumor cell apoptosis ${ }^{[14]}$, anti-tumor drug sensitization $^{[6]}$, inhibiting tumor angiogenesis ${ }^{[3]}$ and other aspects has attracted widespread attention. In this study, RON inhibitor Cp-1 was combined with emodin to act on bladder cancer cells, the results showed that in group C, D and group CD, RON expression level of cells decreased obviously and the cell survival rate was lower than that in group C and D and the cell survival rate is lowest in group $\mathrm{CD}$. The differences group $\mathrm{C}$ and $\mathrm{D}$ were statistically significant. This suggests that the $\mathrm{Cp}-1$ and emodin can inhibit the expression of RON, and can significantly inhibit bladder cancer cell proliferation and the two have a synergistic effect.

Apoptosis is a programmed death and an important selfstabilizing mechanism of the organism. The general apoptotic pathways are divided into endogenous (mitochondrial) and exogenous pathways. The Bcl2 proto-oncogene is located on the mitochondrial membrane and plays an inhibitory role in apoptosis and is the common intersection of various signal transduction pathways. Overexpression of Bcl-2 can enhance cell resistance to most DNA damage factors and inhibit target cell apoptosis induced by most chemotherapeutic drugs ${ }^{[8]}$. The results of this study showed that Bcl-2 was highly expressed of bladder cancer cells in the control group and the expression of Bcl-2 was down-regulated after the intervention of $\mathrm{Cp}-1$ and emodin and the expression level of Bcl-2 was the lowest in the combined treatment group. Caspase- 3 is a very important protein molecule in the apoptosis and many apoptosis pathways induce apoptosis through Caspase-3 signal transduction ${ }^{[15]}$. Our results showed that compared with group $\mathrm{B}$, the expression of caspase-3 in groups C, D and CD was significantly increased and the expression level in group CD was the highest. Therefore, it can be inferred that both $\mathrm{Cp}-1$ and emodin may induce early apoptosis of bladder cancer cells by down-regulating the expression level of Bcl-2 and inducing the increase expression of caspase-3.

In conclusion, emodin combined with $\mathrm{Cp}-1$ can enhance apoptosis and inhibit proliferation of bladder cancer cells. This experiment shows that its mechanism may be through inhibiting the expression of RON, down-regulating the expression of $\mathrm{Bcl}-2$ and enhancing the expression of caspase- 3 in bladder cancer cells and ultimately promoting tumor cell apoptosis. This study will provide experimental evidence for the clinical application of emodin combined with $\mathrm{Cp}-1$ in the treatment of bladder cancer and open up a new way for the clinical treatment of bladder cancer.

\section{Acknowledgement:}

This work was supported by Ningbo Medical Science and Technology Plan Project (No. 2017A06), Zhejiang Province Chinese Medicine Appropriate Technology Cultivation Project (No. 2018ZT005).

\section{Conflicts of interest:}

The authors report no conflicts of interest.

\section{REFERENCES}

1. Davies B, Waxman J, Wasan H, Abel P, Williams G, Krausz $\mathrm{T}$, et al. Levels of matrix metalloproteases in bladder cancer correlate with tumor grade and invasion. Cancer Res 1993;53(22):5365-9.

2. Heney NM, Ahmed S, Flanagan MJ, Frable W, Corder MP, Hafermann MD, et al. Superficial bladder cancer: progression and recurrence. J Urol 1983;130(6):1083-6.

3. Liu H, Gu LB, Tu Y, Hu H, Huang YR, Sun W. Emodin ameliorates cisplatin-induced apoptosis of rat renal tubular cells in vitro by activating autophagy. Acta Pharmacol Sin 2016;37(2):235-45.

4. Cha TL, Qiu L, Chen CT, Wen Y, Hung MC. Emodin downregulates androgen receptor and inhibits prostate cancer cell growth. Cancer Res 2005;65(6):2287-95.

5. Ok S, Kim SM, Kim C, Nam D, Shim BS, Kim SH, et al. Emodin inhibits invasion and migration of prostate and lung cancer cells by downregulating the expression of chemokine receptor CXCR4. Immunopharmacol Immunotoxicol 2012;34(5):768-78.

6. Sui JQ, Xie KP, Zou W, Xie MJ. Emodin inhibits breast cancer cell proliferation through the ER $\alpha$-MAPK/Aktcyclin D1/Bcl-2 signaling pathway. Asian Pac J Cancer Prev 2014;15(15):6247-51.

7. Wang H, Dong Y, Xiu ZL. Microwave-assisted aqueous two-phase extraction of piceid, resveratrol and emodin from Polygonum cuspidatum by ethanol/ammonium sulphate systems. Biotechnol Lett 2008;30(12):2079-84.

8. Wang C, Wu X, Chen M, Duan W, Sun L, Yan M, et al. Emodin induces apoptosis through caspase 3-dependent pathway in HK-2 cells. Toxicology 2007;231(2-3):120-8.

9. Wei W, Di J, Rasul A, Zhao C, Millimouno FM, Tsuji I, et al. Dracorhodin perchlorate induces apoptosis in bladder cancer cells through Bcl-2, Bcl-XL, survivin down-regulation and caspase-3 activation. Bangladesh J Pharmacol 2013;8(3):27682. 
10. Lin Y, Fukuchi J, Hiipakka RA, Kokontis JM, Xiang J. Upregulation of $\mathrm{Bcl}-2$ is required for the progression of prostate cancer cells from an androgen-dependent to an androgenindependent growth stage. Cell Res 2007;17(6):531-6.

11. Jinga DC, Blidaru A, Condrea I, Ardeleanu C, Dragomir C, Szegli G, et al. MMP-9 and MMP-2 gelatinases and TIMP-1 and TIMP-2 inhibitors in breast cancer: correlations with prognostic factors. J Cell Mol Med 2006;10(2):499-510.

12. Burlacu A. Regulation of apoptosis by Bcl-2 family proteins. J Cell Mol Med 2003;7(3):249-57.

13. Borner $\mathrm{C}$, Martinou I, Mattmann $\mathrm{C}$, Irmler $\mathrm{M}$, Schaerer $\mathrm{E}$, Martinou JC, et al. The protein bcl-2 alpha does not require membrane attachment, but two conserved domains to suppress apoptosis. J Cell Biol 1994;126(4):1059-68.
14. Ying Y, Qingwu L, Mingming X, Zhenju S, Chaoyang T, Zhengang T. Emodin: One main ingredient of shufeng jiedu capsule reverses chemoresistance of lung cancer cells through inhibition of EMT. Cell Physiol Biochem 2017;42(3):1063-72.

15. Deng G, Ju X, Meng Q, Yu ZJ, Ma LB. Emodin inhibits the proliferation of PC3 prostate cancer cells in vitro via the Notch signaling pathway. Molecular medicine reports. 2015 Sep 1;12(3):4427-33.

This is an open access article distributed under the terms of the Creative Commons Attribution-NonCommercial-ShareAlike 3.0 License, which allows others to remix, tweak, and build upon the work non-commercially, as long as the author is credited and the new creations are licensed under the identical terms

This article was originally published in a special issue, "Clinical Research in Pharmaceutical and Biomedical Sciences" Indian J

Pharm Sci 2021:83(1)spl issue "192-197". 